\title{
A study of Faradaic phenomena in activated carbon by means of macroelectrodes and single particle electrodes
}

\author{
V. Ruiz ${ }^{\mathrm{a}}$, H. Malmberg ${ }^{\mathrm{b}},{ }^{*}$ C. Blanco ${ }^{\mathrm{a}}$, A. Lundblad ${ }^{\mathrm{b}}$ P. Björnbom ${ }^{\mathrm{b}}$ and R. Santamaría ${ }^{\mathrm{a}}$ \\ ${ }^{a}$ Instituto Nacional del Carbón, CSIC, Apdo. 73, 33080 Oviedo, Spain \\ ${ }^{b}$ The Royal Institute of Technology, Department of Chemical Engineering and Technology, SE- \\ 10044 Stockholm, Sweden
}

\begin{abstract}
.-
The electrochemical behaviour of a chemically activated carbon with oxygencontaining surface groups was studied using a conventional macroelectrode configuration with disc electrodes and the single particle microelectrode technique. The results of both experimental set-ups were compare taking into account the visible peaks of the surface groups, capacitance and Faradaic currents. Galvanostatic cycling and cyclic voltammetry performed at different potential windows clearly indicated that the microelectrode configuration was more sensitive to Faradic phenomena (i.e. oxygenated functional groups). The incorporation of mainly $\mathrm{CO}_{2}$-evolving groups after positive polarization may cause the degradation of the carbon material, leading to a distortion in its capacitive behaviour as a result of a restriction of the available surface area.
\end{abstract}

\footnotetext{
* Corresponding author: clara@,incar.csic.es; Fax.: + 34985297662
} 


\section{1.- INTRODUCTION}

In a three-electrode cell, the formation of an active material into a manageable working electrode often involves a polymer. The elaboration of disc-type electrodes (macroelectrodes) is generally used for the characterization of the performance of an active material. The addition of polymer to the activated carbon may cause a reduction in accessible surface area for the electrolyte (an effect that is strongly influenced by the way in which the polymer and the carbon are mixed) [1]. The polymer also causes a significant reduction in the electrical conductivity of the electrode [2]. Therefore, the electrochemical behaviour obtained using a macroelectrode may be influenced not only by the activated carbon itself but also by the presence of the polymer.

By using the configuration described above, Ruiz et al. [3] investigated a chemically activated carbon noting the Faradaic behaviour of the material at the potentials where quinone/hydroquinone reactions are believed to take place. This carbon had up to $3.5 \%$ oxygen and $1.2 \mathrm{mmol} \mathrm{CO} / \mathrm{g}$ as determined by temperature-programmed desorption (TPD). They found no distinct peaks in the interval 0.2 to $-0.8 \mathrm{~V}$ vs. $\mathrm{Hg} \mid \mathrm{HgO}$. Smeared out humps and variations of both anodic and cathodic currents with surface functionality concentrations were attributed to the oxidation/reduction of these functionalities. Béguin et al. [4] studied activated carbons with $10 \%$ and $6 \%$ oxygen after activation with $\mathrm{KOH}$. The activated carbons were mixed with polymeric binder and graphite before the preparation of the electrodes. They did not find any distinct peaks but attributed anodic and cathodic humps (smeared out in the scans up to $-1.7 \mathrm{~V}$ ) found at $-0.4 \mathrm{~V}$ and $-1 \mathrm{~V}$ vs. $\mathrm{Hg} \mid \mathrm{HgO}$ to the oxidation and reduction of surface functionalities. Jurewicz et al. [5] studied an activated carbon with $0.4 \mathrm{meq} / \mathrm{g}$ carbonyl 
groups determined by acid/base titration. The electrodes were prepared using the activated carbon without adding any polymeric binder. No Faradaic peaks were observed when scanning between +0.05 and $-0.8 \mathrm{~V}$. The electrochemical behaviour of the chemically activated carbon studied by Ruiz et al. [3] was therefore slightly different to that observed in the literature.

In the single particle microelectrode technique [6], a single carbon particle is used as working electrode. Thus, the information obtained corresponds exclusively to the activated carbon. Two key aspects in the cyclic voltammetry experiments performed in the microscopic configuration are the low current intensities registered, with the subsequent reduction in the ohmic drop (IR), and the increased sensitivity to both the Faradaic and non-Faradaic currents generated within the pore system. It has previously been shown that the microelectrode technique may yield more distinct peaks when Faradaic phenomena are studied due to smaller potential gradients in the particles themselves compared to those of the macroscopic electrodes [7]. Using a nanoporous carbon derived from $\mathrm{SiC}$ with a very low content in functional groups, Zuleta et al. [7] observed small but distinct peaks. Under similar conditions, using an activated carbon with functional groups (1.2 mmol/g CO determined by TPD), Malmberg et al. [8] described larger peaks in the interval from +0.2 to $-0.2 \mathrm{~V}$ and +0.2 to $-0.9 \mathrm{~V} v s$. $\mathrm{Hg} \mid \mathrm{HgO}$. The nature of the active material studied in this paper differed in structure and in chemical composition from the carbide-derived activated carbon used in previous studies $[7,9,10]$. These results raise the question whether differences in peak observations between the two methods are due to the higher sensitivity of the microparticle method or simply due to circumstantial variations in the activated carbon chemistry. In order to clarify this 
point, experiments were carried out, for the first time to our knowledge, so that both configurations (disc-type electrode and single-particle electrode) with the same active material and under similar experimental conditions (electrolyte solution, current density and potential window) could be compared.

\section{2.- EXPERIMENTAL}

\section{1.- Material}

A chemically activated carbon was produced from mesophase pitch (AR24). This pitch, derived from synthetic naphthalene and thus low in ash content, was chemically activated with $\mathrm{KOH}\left(3: 1 \mathrm{KOH}\right.$ to carbon ratio) at $700{ }^{\circ} \mathrm{C}$ for $1 \mathrm{~h}$. The activation procedure and the characteristics of the activated carbon obtained have been previously described [3]. The structural properties of this highly microporous activated carbon were studied by nitrogen adsorption at $77 \mathrm{~K}$, providing a total pore volume of $0.85 \mathrm{~cm}^{3} / \mathrm{g}$ and a BET area of $2000 \mathrm{~m}^{2} / \mathrm{g}$. The sample AC has a considerable amount of oxygen functionalities, 3.5 wt. \% oxygen and a negligible amount of nitrogen obtained by direct determination. The sample has a low $\mathrm{pH}, 2.8$. Additionally, it has a large amount of $\mathrm{CO}$ evolving groups, such as phenols, ethers and carbonyl groups, which were determined by temperature-programmed desorption (TPD) following the method previously described by Ruiz et al. [3]. The sample was placed in a U-shape quartz cell and treated at $100{ }^{\circ} \mathrm{C}$ for $1 \mathrm{~h}$ under a He flow of $50 \mathrm{~mL} / \mathrm{min}$. Then, the temperature was raised at $10^{\circ} \mathrm{C} / \mathrm{min}$ to $1000^{\circ} \mathrm{C}$. On-line mass spectrometry was used to measure the decomposition products $\left(\mathrm{CO}\right.$ and $\left.\mathrm{CO}_{2}\right)$. 
The electro-oxidation of the activated carbon was carried out in a conventional macroelectrode system, without using any binder. Around $100 \mathrm{mg}$ of material was subjected to electro-oxidation at $+0.3 \mathrm{~V}$ in a $\mathrm{N}_{2}$ bubbling solution of $6 \mathrm{M} \mathrm{KOH}$, the same electrolyte as for the other experiments. After the electro-oxidation process, the sample was washed using distilled water and then dried in a vacuum oven at $110{ }^{\circ} \mathrm{C}$ overnight. The amount of oxygen functional groups incorporated after this electrochemical treatment was evaluated by TPD under inert atmosphere $(\mathrm{He})$. Changes is surface area were negligible as the BET surface area decreased from 2000 to $1989 \mathrm{~m}^{2} / \mathrm{g}$.

\section{2.- Conventional three-electrode cell configuration}

Coin-type electrodes were prepared by mixing the activated carbon (90 wt. \%) with polyvinylidene fluoride, PVDF (10 wt. \%). The working electrodes were fabricated from this mixture by pressing $\sim 30 \mathrm{mg}$ of mixture into $8 \mathrm{~mm}$ (diameter) discs with a thickness of $200 \mu \mathrm{m}$. Platinum and $\mathrm{Hg} \mid \mathrm{HgO}$ were used as the counter and reference electrodes (0.098 V versus NHE), respectively. The electrochemical measurements were performed in a $6 \mathrm{M} \mathrm{KOH}$ aqueous solution.

\section{3.- Single particle microelectrode}

The cell for the single particle microelectrode technique is mounted on a microscope, and a single particle of the activated carbon is brought into contact with a highly conductive carbon fibre attached to a gold probe surrounded by de-aired electrolyte. This acts as the working electrode. A Ni felt with a larger surface area than the working electrode was used as counter electrode. $\mathrm{Hg} \mid \mathrm{HgO}$ was used as the reference electrode. 
Particles of the activated carbon $(\sim 100 \mu \mathrm{m})$ were used for the single particle experiments. For a detailed description of the single particle microelectrode technique and further details regarding the absence of electrochemical activity of the carbon fibre, see references $[6,9]$.

\section{4.- Experimental procedures}

The electrochemical measurements were performed in both cases with an Autolab potentionstat supplied by Eco Chemie. Cyclic voltammetry experiments were carried out at a sweep rate of $1 \mathrm{mV} / \mathrm{s}$ and galvanostatic cycling was performed at a current density of $230 \mathrm{~mA} / \mathrm{g}$. The potential window used was kept inside the limits of the thermodynamic stability of the electrolytic medium, $6 \mathrm{M} \mathrm{KOH}$. All the potentials refer to $\mathrm{Hg} \mid \mathrm{HgO}$ reference electrode. Several discs and particles were analyzed in order to obtain reliable data. Reproducible results were obtained in all of the cases.

Using a digital microscope it was possible to obtain several images of the particles studied. With the help of the carbon fibre, controlled with a micromanipulator, each particle was moved around at different angles and its volume was estimated. Additionally, the apparent density of the active material was evaluated according to the method described elsewhere [11]. Once the volume of each particle and the bulk density of the material are known, the gravimetric specific capacitance values provided by the microparticle technique can be determined and compared to the data provided by the macroscopic set-up. 


\section{3.- RESULTS AND DISCUSSION}

Activated carbon has been studied in $\mathrm{KOH}$ electrolyte solution using both macroscopic disc electrodes and with the single microparticle electrode method in a three electrode setup. Although a considerable standard deviation in quantitative results has been reported [12], in the present case all the particles exhibited the same electrochemistry.

Figure 1a shows the results obtained by means of cyclic voltammetry using both configurations. In a narrow potential window (0 to $-0.2 \mathrm{~V})$, the typical rectangular behaviour of a double layer capacitor can be observed. The specific capacitance values estimated in both cases are fairly equal (see Figures 1 and 2), despite the error possibly introduced when estimating the mass of the microelectrode particle. These values are comparable to those reported for other activated carbons obtained from similar precursors $[13,14]$. As expected, the effect of resistance shown by the microscopic device was less pronounced. This could be because of the better contact between the fibre and the particle than between the disc and the current collector, the significantly lower currents measured, the lower influence of the gradients and because of the absence of polymer in the microelectrode.

Figure $1 \mathrm{~b}$ provides a comparison of the galvanostatic polarization obtained in both setups for the same potential window $(0,-0.2 \mathrm{~V})$. Both cycles show the triangular shape typical of double layer capacitors. As observed before in the cyclic voltammograms, the effect of resistance is more pronounced for the macroscopic device. The ohmic drop of the disc electrode does not deviate remarkably from data in the literature $[4,5]$. 
The cut-off value increased towards more negative values (starting at $0,-0.2 \mathrm{~V}$ and progressively increasing to $0,-0.9 \mathrm{~V}$ ). The voltammetry characteristics obtained show significant differences for each configuration (Figures $2 a$ and $2 b$ ). The main difference can be observed at potentials between -0.4 and $-0.5 \mathrm{~V}$. In the microscopic system a redox couple attributed to the quinone/hydroquinone couple is visible. However, for the conventional disc-type configuration there is no clear sign of any similar effect. It is also worth noting that the hump is much more pronounced in the cathodic branch. Previous studies have suggested that smaller electrodes may have a more uniform potential [7]. A large electrode may suffer from potential gradients, which would explain the absence of detail in these voltammograms. The reaction and diffusion in the particles [15] explains why the characteristic diffusion length (i.e. particle volume divided by external particle surface in contact with the fluid) of a spherical particle is only one sixth the effective diffusion length of a slab-shaped disc electrode with the same thickness as the particle size. Similar reasons explaining why Faradaic phenomena occurred in $\mathrm{NiOOH} / \mathrm{Ni}\left(\mathrm{OH}_{2}\right)$ microelectrodes but not in composite electrodes were proposed by Kim et al. [16]. However, their nickelhydroxide system differed significantly from the activated carbon employed in the present study.

From Figure 2 it can be seen that the values of the positive and the negative currents are different in each configuration, which is indicative of the influence of Faradaic currents. This behaviour is more pronounced when the potential range shifts to more negative values. The voltammograms also show a slight increase in the anodic current as the potential window moves towards the cut-off value, which points to reversible hydrogen adsorption [4]. Additionally, an increasing cathodic current can be observed at around $0.9 \mathrm{~V}$ (Figure $2 \mathrm{a}$ and $2 \mathrm{~b}$ ) due to water decomposition (i.e. $\mathrm{H}_{2}$ evolution) and hydrogen 
adsorption in the carbon material. As might be expected, this effect was more significant for the microelectrode due to its shorter characteristic length.

Galvanostatic cycling in the potential interval 0 to $-0.7 \mathrm{~V}$ at a current density of $230 \mathrm{~mA} / \mathrm{g}$ also reveasls significant differences between both devices (Figure 3). While the discharge branch is linear and quite similar in slope in both cases, the charging branch for the single-particle device has two distinct parts, with a sharp change in slope. In the cycle corresponding to the macroscopic device, only a slight curvature in the charging branch can be observed. This non-capacitive behaviour is due to Faradaic currents occurring at the same time as the double layer charging current [17]. These Faradaic currents are usually attributed to both reversible (e.g. reversible redox reactions of surface functional groups of the activated carbon or hydrogen adsorption) and irreversible processes (e.g. hydrogen evolution or irreversible reduction of functional groups in the carbon surface). The linearity of the discharge branch seems to indicate that there are irreversible processes involved in the charge. This may be correlated with the asymmetry of the humps observed in the voltammograms at around $0.5 \mathrm{~V}$ (see Figure 2a). This shows that both reversible and irreversible phenomena are occurring simultaneously at these potentials.

The electrochemical processes that take place during positive polarization in carbon materials have been studied in literature $[7,18,19]$. When moderate oxidation takes place, the morphology of the carbon material does not change significantly, although some oxygen functional groups can be created on the surface of the material (i.e., hydroxyl groups) leading to an improvement in wettability $[18,20]$. However, strong oxidation can cause degradation of the carbon material, resulting in the evolution of $\mathrm{CO}$ 
and $\mathrm{CO}_{2}$. The effect of trapping gaseous $\mathrm{CO}$ and $\mathrm{CO}_{2}$ in porous materials is important since the solubility of these gases in aqueous media is high. The reaction following solvation produces carbonate ions $\left(\mathrm{CO}^{2-}\right)$, a well-known problem when working with $\mathrm{KOH}$-solutions [10]. The crystalline residue, often seen in electrochemical cells that are subjected to atmospheric conditions, is not soluble in basic media once formed and will therefore impact the experiments conducted afterwards.

The study of the behaviour of the activated carbon at positive potentials is limited by the thermodynamic stability of the $\mathrm{KOH}$ used as the electrolyte (+0.3 V vs. $\mathrm{Hg} \mid \mathrm{HgO})$. Figure 4 shows the curves obtained when cycling the material in both configurations, up to the positive limit of the decomposition of the solution. There is a great asymmetry, resulting from the oxidation of the carbonaceous material together with some oxygen evolution at positive potentials [21].

In order to study the effect of positive polarization on the carbon material, cycling into the capacitive region was performed after subjecting the electrode to $+0.3 \mathrm{~V}$. In the case of the microelectrode (Figure 5a), irreversible damage is caused. The possibility of effectively using the electrode as a double layer capacitor was thus lost after subjecting the particle to $+0.3 \mathrm{~V}$ due to irreversible oxidation of the carbon. The results presented here indicate that the peculiar characteristics of the activated carbon used (i.e. significant content in oxygen functionalities) make it more sensitive to positive polarization than the pristine material used by Zuleta et al. [7], where a decreasing trend in the effective diffusivity (i.e. reduced mass transport) was observed. A similar effect was observed in the macroscopic electrode (Figure 5b) although in this case the degradation of the carbon material is beyond doubt after subjecting the electrode to 
$+0.4 \mathrm{~V}$. This confirms the greater sensitivity of the microelectrode technique compared to the macroscopic device. The novelty of the present study is that the oxygen functionalities are introduced during the chemical activation of the carbon prior to any electrochemical characterization. It is therefore likely that these groups play an influential role in the electrochemical behaviour at positive potentials.

In addition to the functionalities already present, other oxygen containing groups introduced into the carbon matrix by positive polarization are believed to be present. For this reason, characterization of the raw material after electro-oxidation was performed. The type and amount of functionalities introduced into the activated carbon after cycling at $+0.3 \mathrm{~V}$ was investigated by electro-oxidation of the activated material without adding any binder. Figure 6 shows the curves corresponding to the evolution of $\mathrm{CO}$ and $\mathrm{CO}_{2}$ for the activated carbon $(\mathrm{AC})$ and for the electro-oxidized sample (EO$\mathrm{AC}+0.3)$. The amount of $\mathrm{CO}$-evolving groups does not change substantially, whereas the groups responsible for the $\mathrm{CO}_{2}$ evolution have increased (from 0.2 to $0.8 \mathrm{mmol} / \mathrm{g}$ ). The overall increase in oxygen determined by direct elemental analysis is also noticeable, as it changes from $3.5 \mathrm{wt} . \%$ in the starting material to $15 \mathrm{wt} . \%$ in EO$\mathrm{AC}+0.3$.

The decrease in capacitance observed after aggressive oxidation of the material is in agreement with previous results obtained by Zuleta et al. [7]. The suggested pathway for such reactions involves a loosely bound $\mathrm{CO}_{2}$ group that dissociates from the carbon surface and reacts further in the electrolyte with $\mathrm{OH}^{-}$to form $\mathrm{CO}^{2-}$. Thus, excessive oxidation leads to chemical changes in the structure of the carbonaceous material, affecting subsequent electrochemical behaviour, including the mobility of the ions. 
Furthermore, the humps indicative of Faradaic processes that are the result of the functional groups present in the material (due to the activation process, illustrated in Figure 2) are still present even after aggressive oxidation (Figure 7). However, it must be pointed out that the electro-oxidation of the activated carbon did not affect the $\mathrm{CO}$ evolving groups to the same extent as it affected the $\mathrm{CO}_{2}$ evolving groups. This finding confirms that quinoid type groups (CO-evolving) were involved in the Faradaic phenomena described previously. It also supports the hypothesis in [7] that functional groups and carbonate ions formed in the pores by electro-oxidation hinder the movement of ions.

\section{4.- CONCLUSIONS}

The specific capacitance values obtained by both techniques are similar. However, the single particle microelectrode technique revealed the occurrence of several important phenomena not clearly visible when using macroscopic disc electrodes to characterize the activated carbons. The microelectrode technique also disclosed the pseudocapacitance caused by Faradaic phenomena in basic media, which are be ascribed to the redox reactions of oxygenated groups and to the irreversible evolution of hydrogen. The electro-oxidation of the carbon surface at positive potentials $(+0.3 \mathrm{~V})$ changes the capacitive behaviour of the material due to pore blockage, which hinders access of the electrolyte to the porous network. However, electro-oxidation did not significantly affect the surface functionality of the single bonded oxygen groups. 
ACKNOWLEDGEMENTS.- This work has been carried out with financial support from MEC (project MAT2004-03480-C02) and FICYT (project IB05-086-C1). V. Ruiz acknowledges a predoctoral research grant awarded by FICYT. 


\section{REFERENCES}

[1] V. Ruiz, C. Blanco, M. Granda, R. Menéndez, R. Santamaría, J. Appl. Electrochem. 37(6) (2007) 717.

[2] S. Yoon, J. Lee, T. Hyeon, S. M. Oh, J. Electrochem. Soc. 147(7) (2000) 2507.

[3] V. Ruiz, C. Blanco, E. Raymundo-Piñero, V. Khomenko, F. Béguin, R. Santamaría, Electrochimica Acta 52 (2007) 4969.

[4] F. Béguin, K. Kierzek, M. Friebe, A. Jankowska, J. Machnikowski, K. Jurewicz, E. Frackowiak, Electrochimica Acta 51 (2006) 2161.

[5] K. Jurewicz, E. Frackowiak, F. Béguin, Appl. Phys A 78 (2004) 981.

[6] M. Bursell, P. Björnbom, J. Electrochem. Soc. 137 (1990), 363.

[7] M. Zuleta, P. Björnbom, A. Lundblad, J. Electrochemical Soc. 153 (2006) A48.

[8] H. Malmberg, V. Ruiz, C. Blanco, R. Santamaria, A. Lundblad, P. Björnbom, Electrochem. Comm. 9 (2007) 2321.

[9] M. Zuleta, M. Bursell, P. Björnbom, A. Lundblad, J. Electroanal. Chem. 549 (2003) 101.

[10] M. Zuleta, P. Björnbom, A. Lundblad, J. Electrochem. Soc. 152(2) (2005) A270.

[11] ASTM Standard Test Method for Apparent Density of Activated Carbon, 1989, Designation: D 2854-89.

[12] H. Malmberg, M. Zuleta, A. Lundblad, P. Björnbom, J. Electrochem. Soc. 153 (10) (2006) A1914.

[13] K. Kierzek, E. Frackowiak, G. Lota, G. Gryglewicz, J. Machnikowski, Electrochim. Acta 49 (2004) 515-523.

[14] H. Shi, Electrochim. Acta 41 (1996) 1633-1639. 
[15] O. Levenspiel, Chemical reaction engineering, John Wiley $\&$ Sons, $3^{\text {rd }}$ Ed., 1999.

[16] H.S. Kim, T. Itoh, M. Nishizawa, M. Mohamedi, M. Umeda, I. Uchida, Int. J. Hydrogen Energy 27 (2002) 295.

[17] B.E. Conway, Electrochemical Supercapacitors, Kluwer Academic, Plenum Publishers, New York, 1999.

[18] A. Rolla, A. Sadkowski, J. Wild, P. Zóltowski, J. Power Sources 5 (1980) 189.

[19] K. Kinoshita, Carbon: Electrochemical and Physicochemical Properties, John Wiley \& Sons, New York, 1988.

[20] K. Horita, Y. Nishibori, and T. Oshima, Carbon 34 (1996) 217.

[21] M.S. Hong, S.H. Lee, S.W. Kim, Electrochem. Solid State Lett. 5 (2002) A227. 
Figure captions

Figure 1.- Electrochemical performance in both configurations in the potential window from 0 to -0.2 V. a) Cyclic voltammetry b) Galvanostatic cycling.

Figure 2.- Cyclic voltammograms obtained when increasing the negative potential window for: a) the microelectrode configuration and b) the macroscopic electrode configuration. Faradaic peaks seen as humps in the microelectrode set-up (adapted from $[8])$.

Figure 3.- Galvanostatic cycling for both configurations in the potential window from 0 to $-0.7 \mathrm{~V}$ at a current density of $230 \mathrm{~mA} / \mathrm{g}$.

Figure 4.- Cyclic voltammograms obtained in both configurations in the potential window from -0.2 to $+0.30 \mathrm{~V}$.

Figure 5.- Cyclic voltammograms performed in: a) the microelectrode configuration and b) in the macroscopic configuration, after cycling up to $+0.3 \mathrm{~V}$.

Figure 6.- Electro-oxidation of activated carbon material used for the electrodes. a) COand b) $\mathrm{CO}_{2}$-evolution curves obtained by TPD.

Figure 7.- Negative polarization after electro-oxidizing a particle. The Faradaic behaviour is still present in the material at a similar potential. 
Figure 1

a)
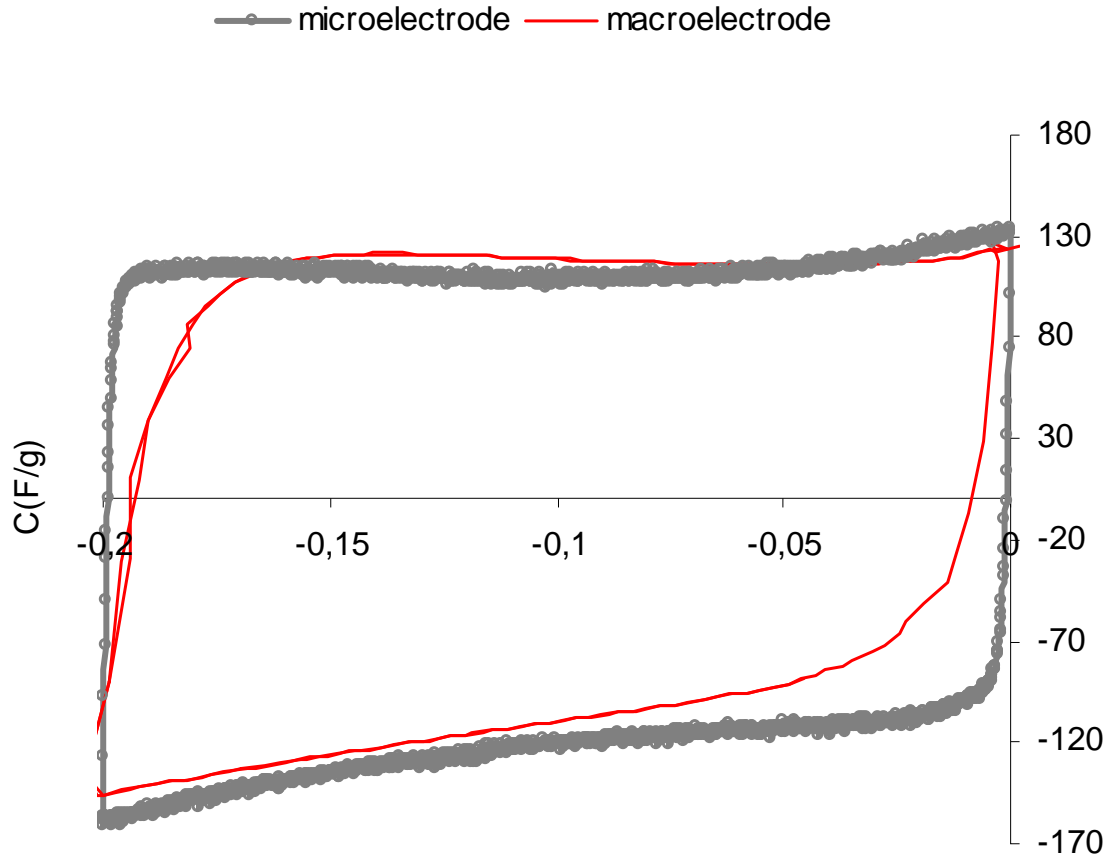

Potential (V)

b)

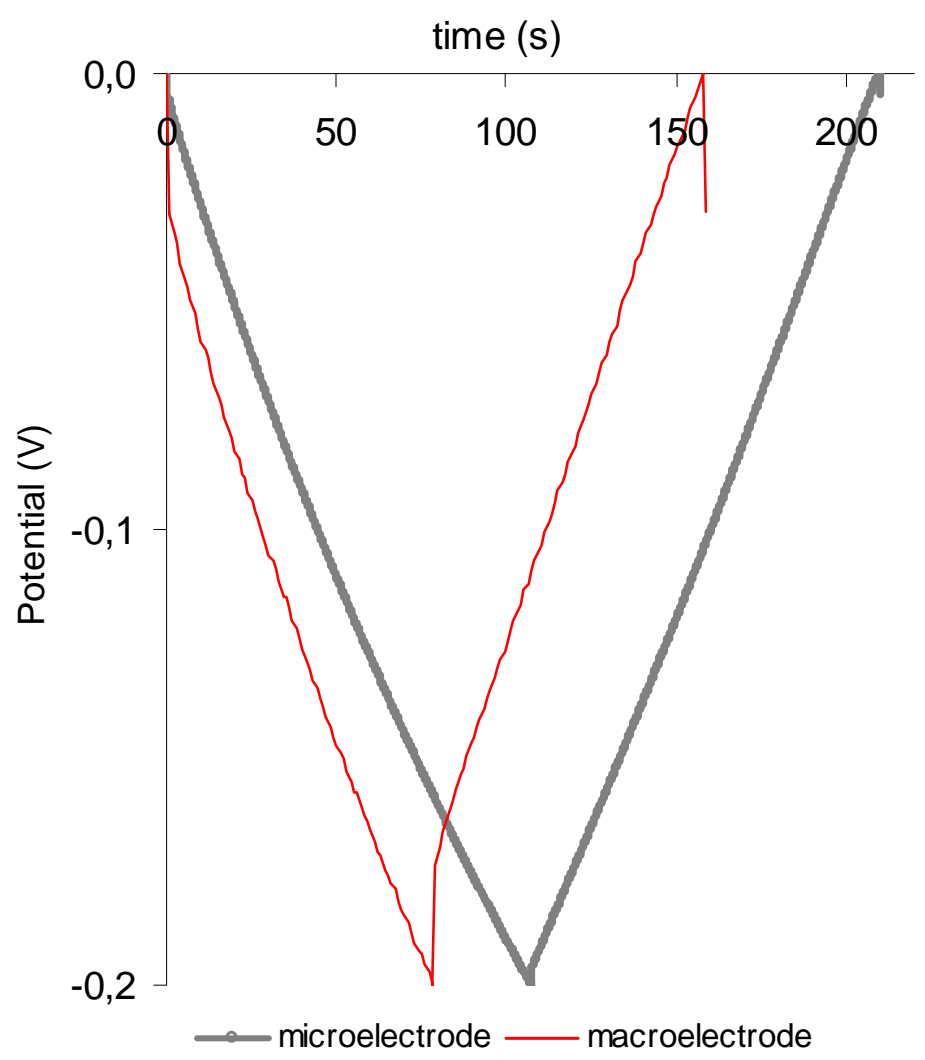


Figure 2

a)

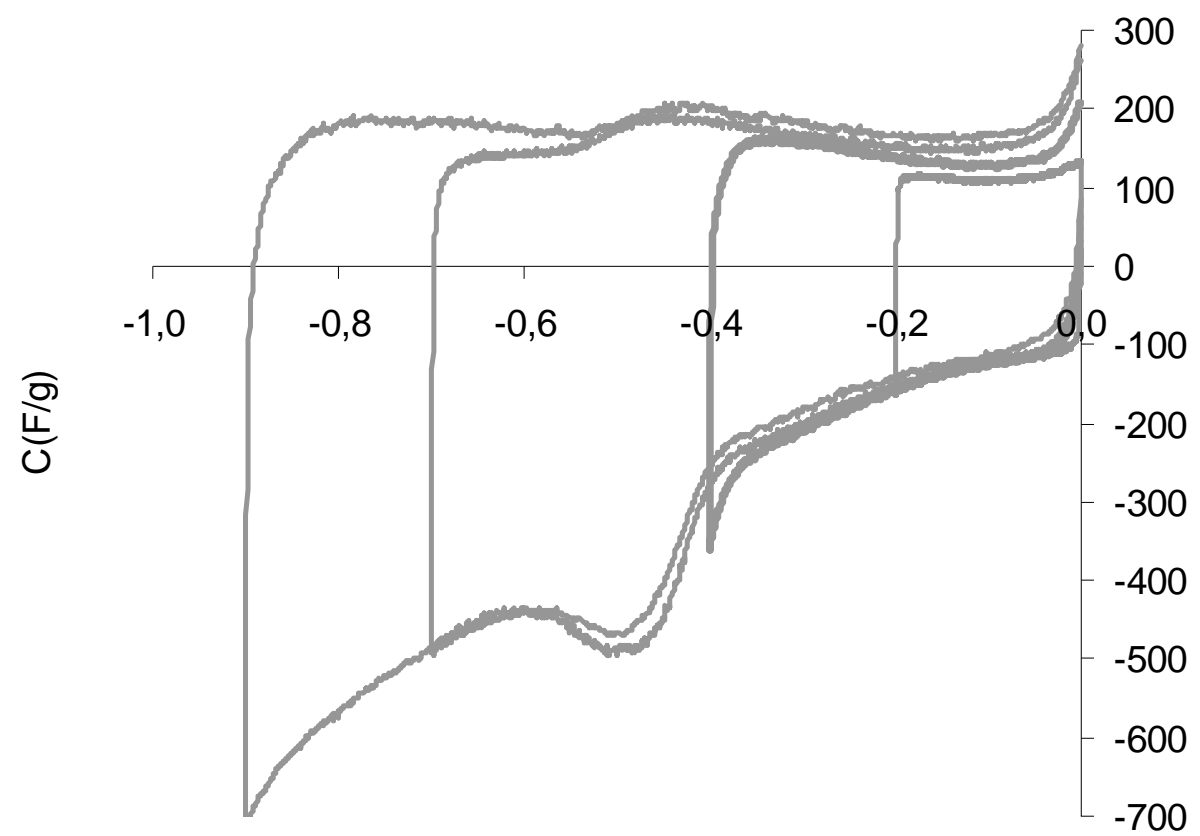

Potential (V)

b)

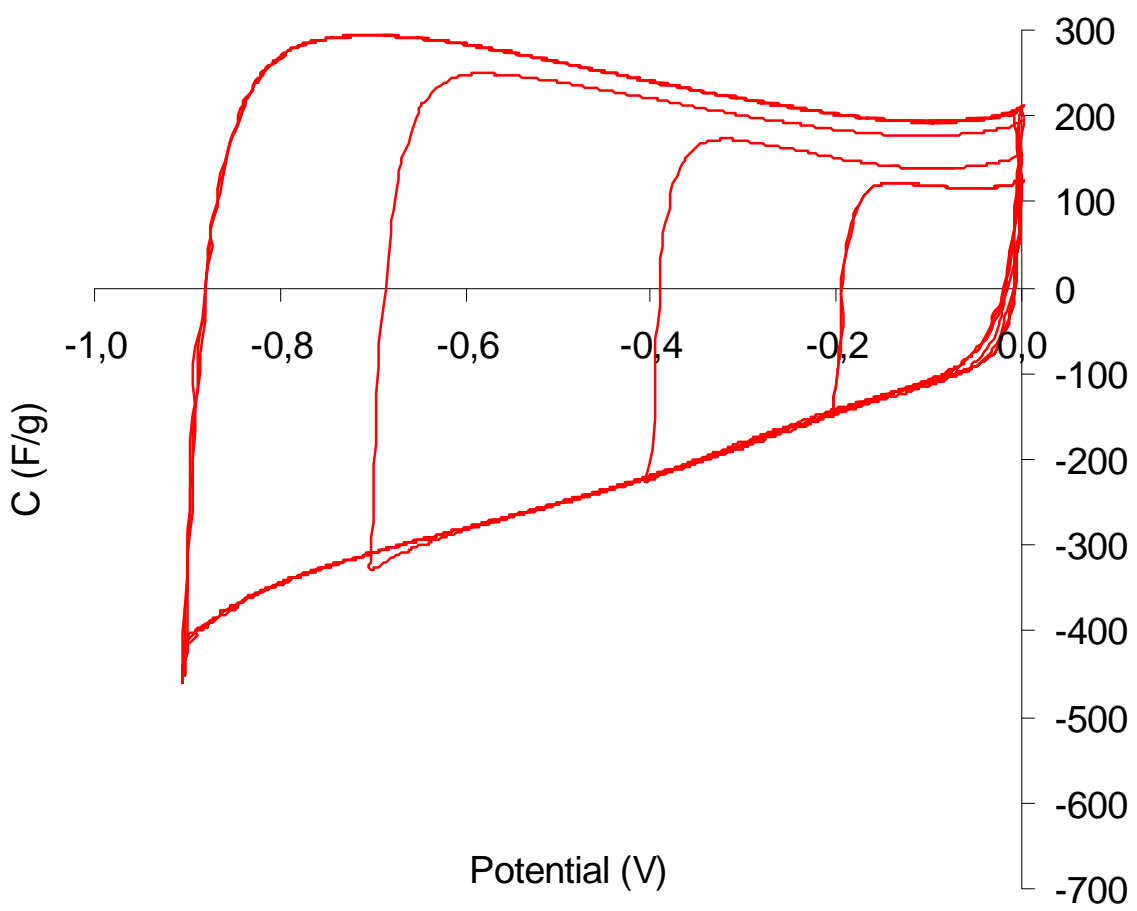


Figure 3

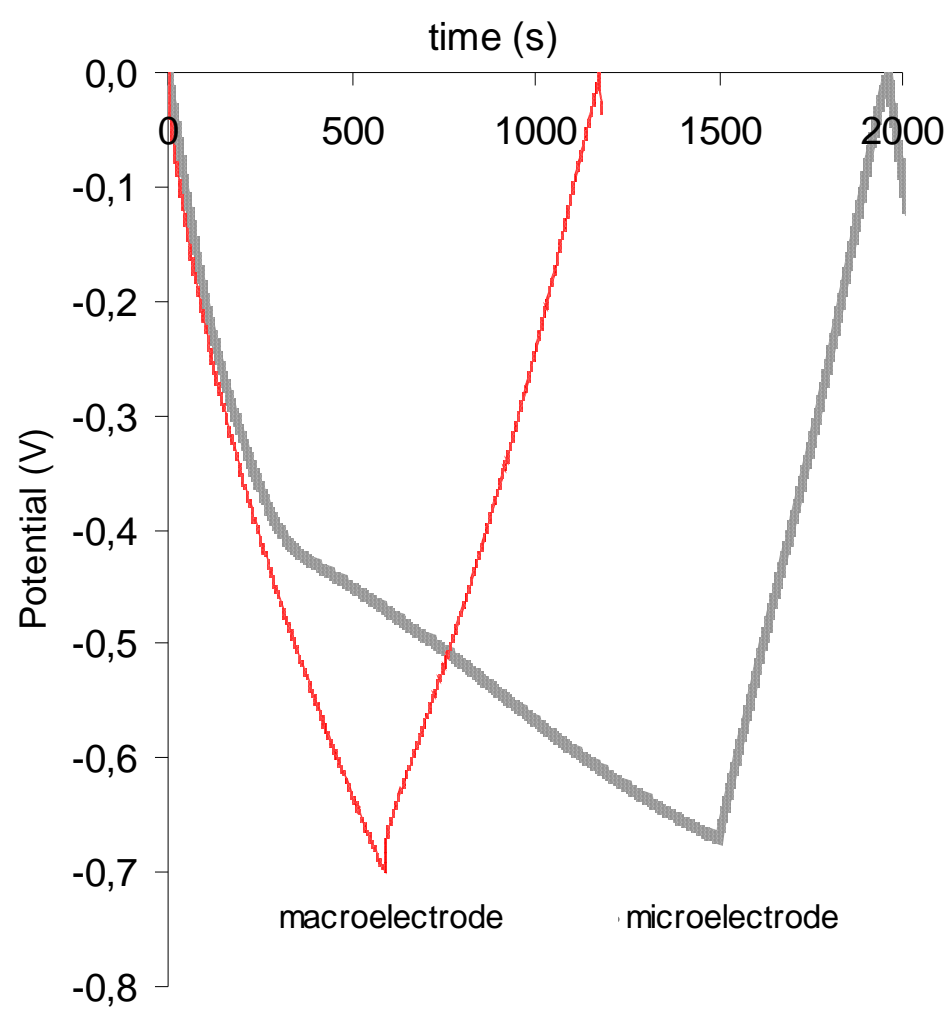


Figure 4

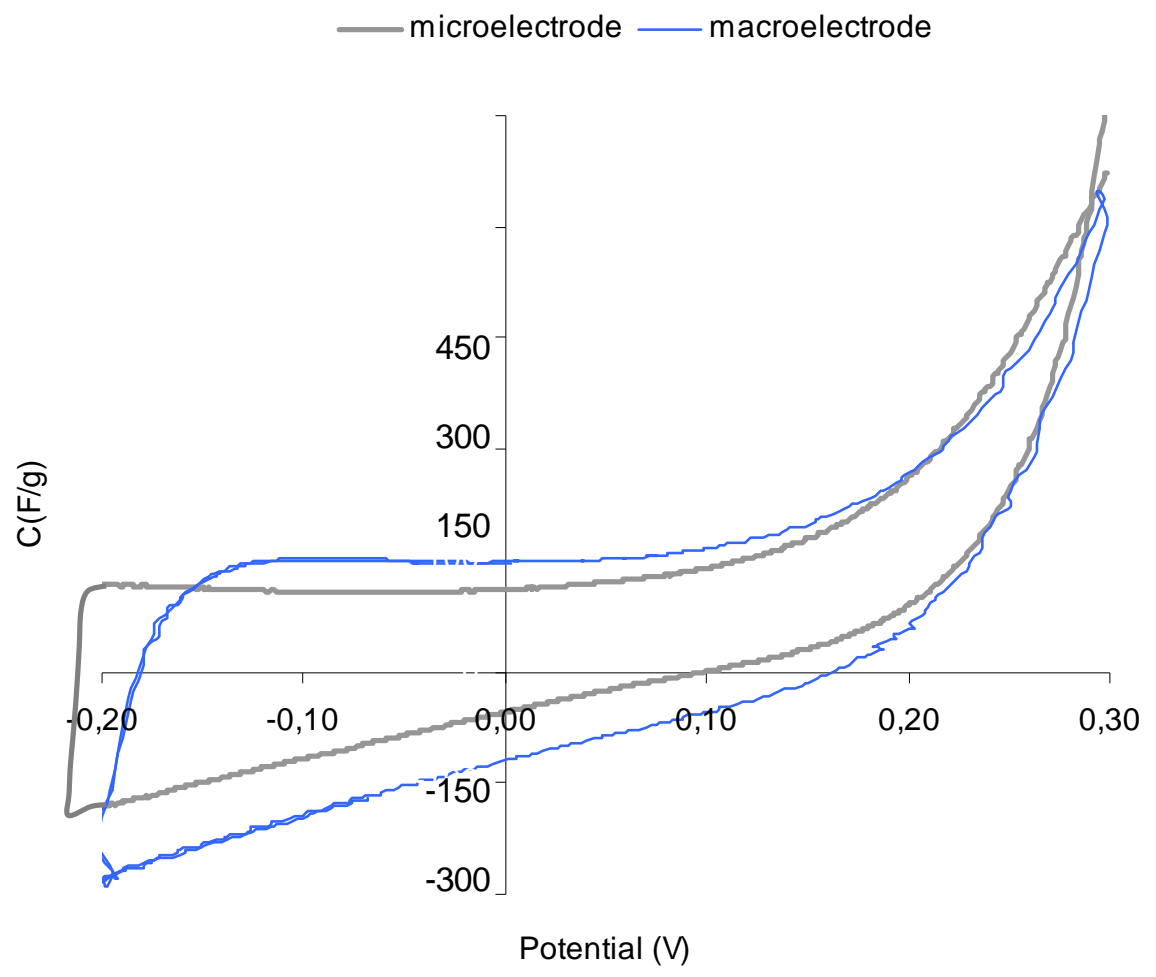


Figure 5

a)

$\ldots$ before cycling at $+0,3 \mathrm{~V} \ldots$ after cycling at $+0,3 \mathrm{~V}$

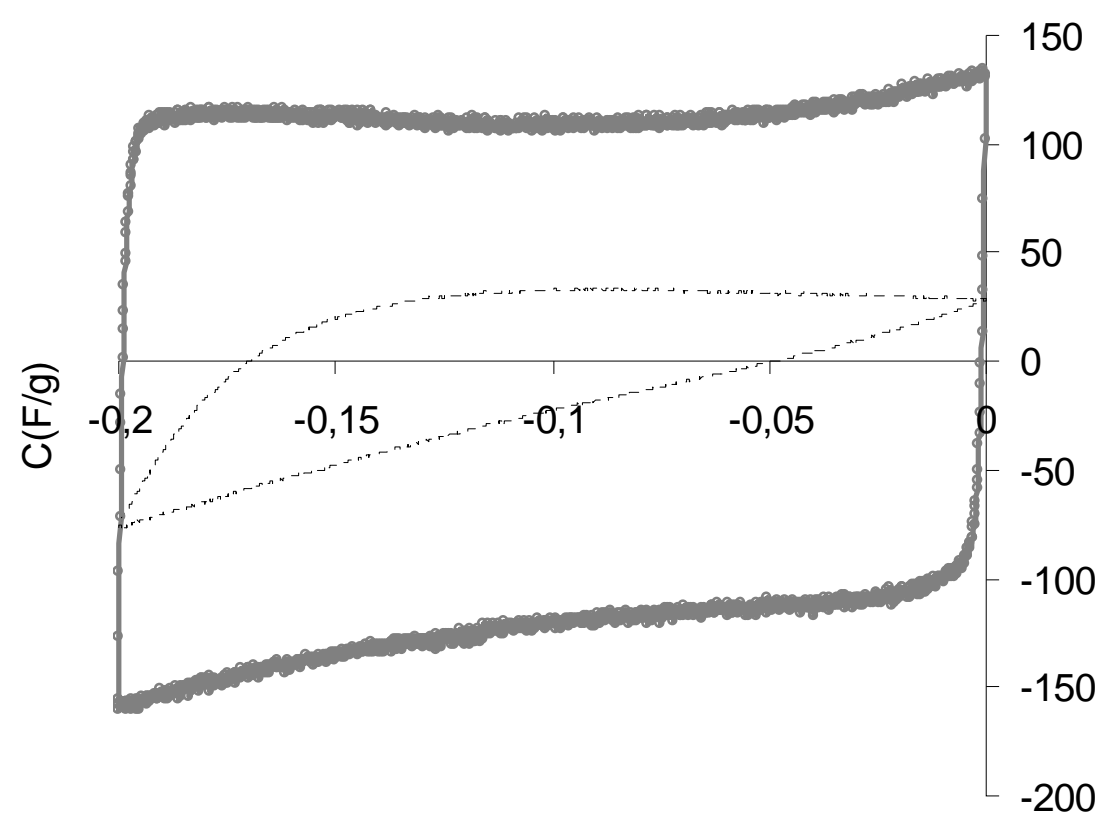

Potential (V)

b)

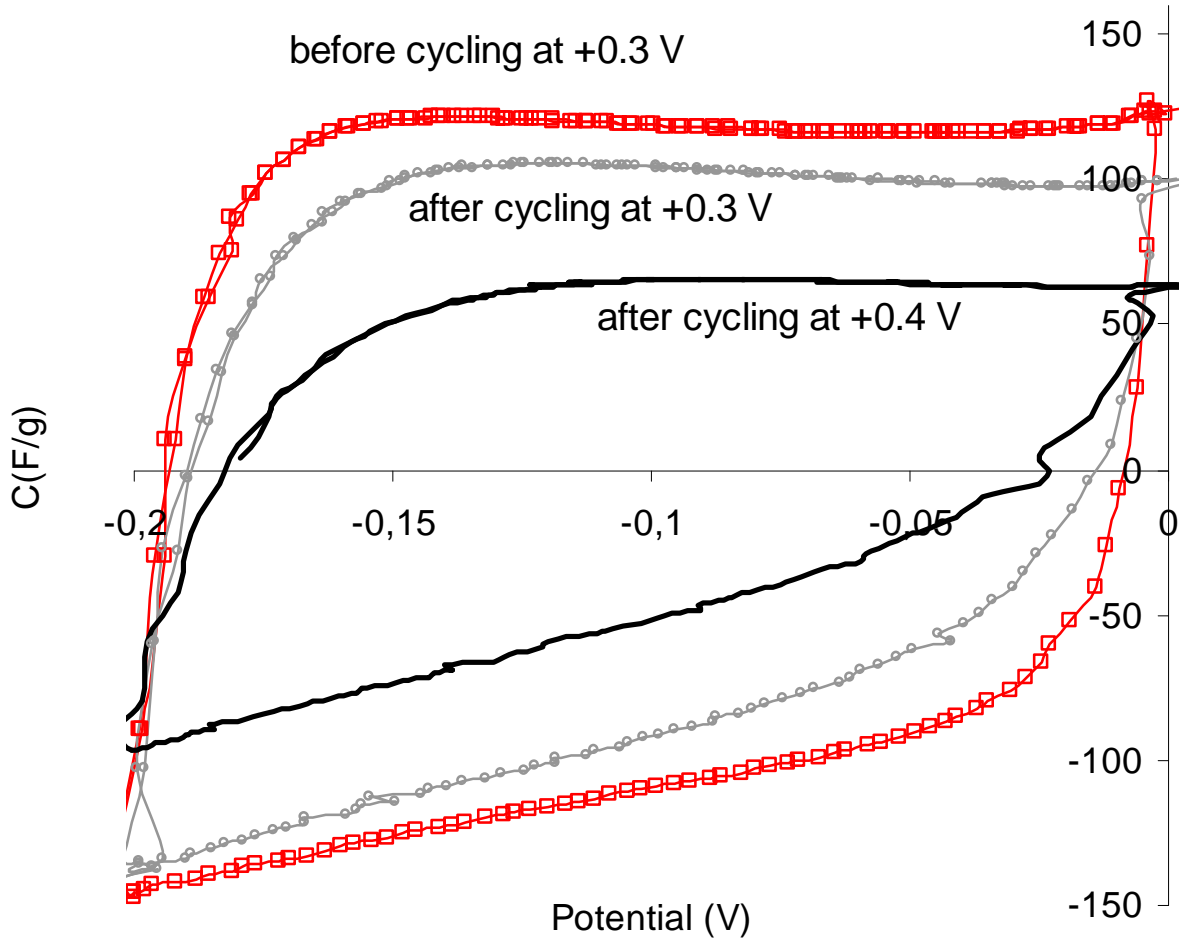


Figure 6

a)

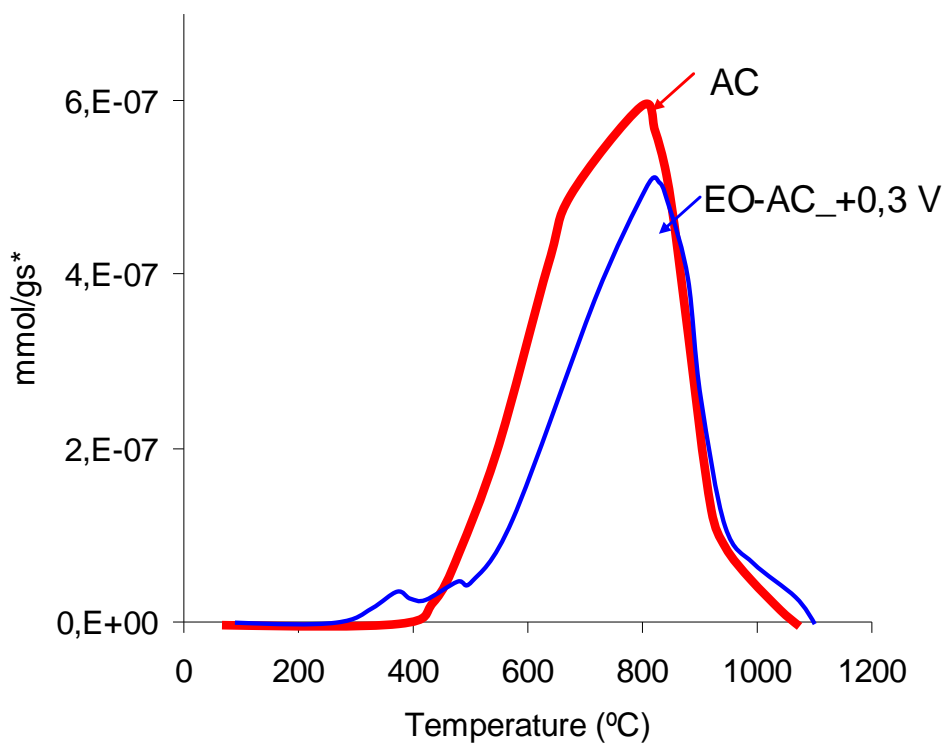

b)

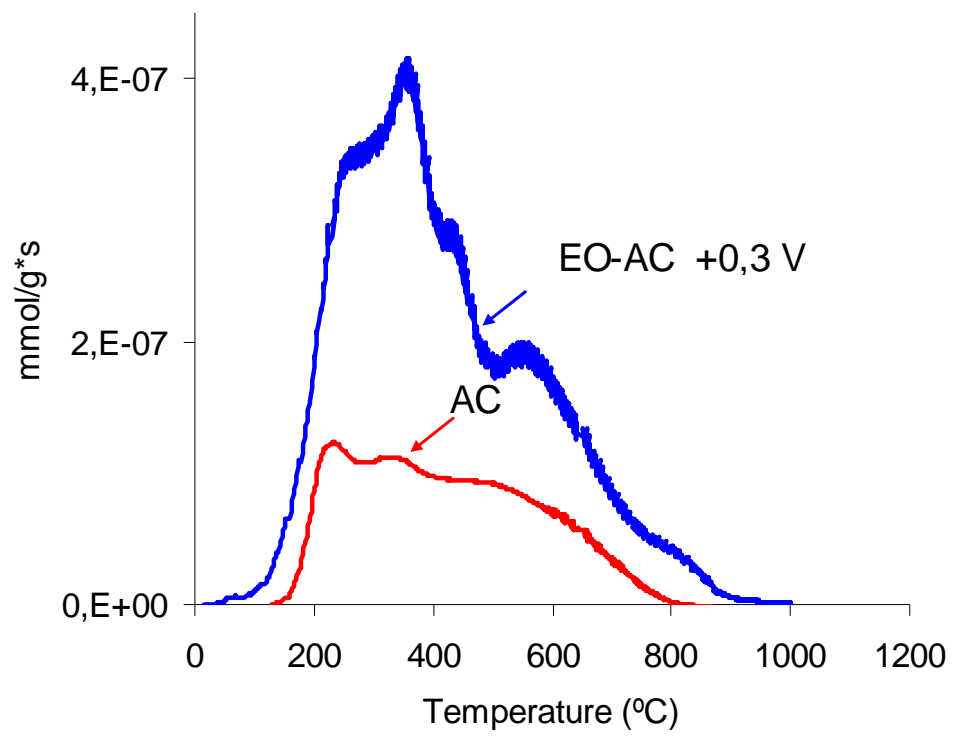


Figure 7

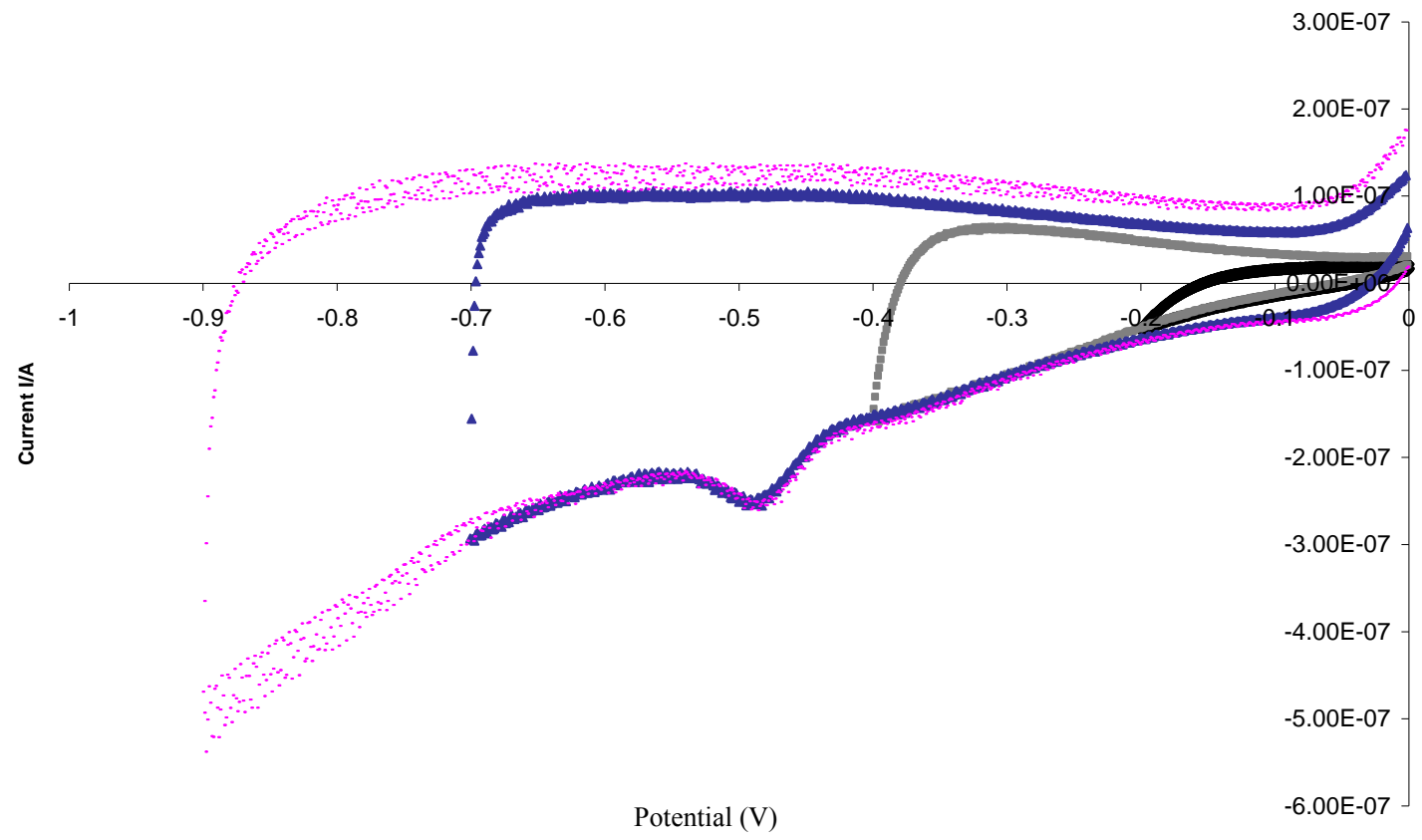

